Focused on the "Portuguese contributions for Structural Integrity"

\title{
Development of hybrid friction stir welding and adhesive bonding single lap joints in aluminium alloys
}

\author{
Ricardo $\mathrm{Maciel}^{(*)}$, Virgínia Infante \\ LAETA, IDMEC, Instituto Superior Técnico, Universidade de Lisboa, Av. Rovisco Pais, 1049-001 Lisboa, Portugal. \\ (*)ricardomaciel@tecnico.ulisboa.pt, bttp://orcid.org/0000-0002-7920-000X \\ Daniel Braga, P.M.G.P. Moreira \\ INEGI, Campus da FEUP, Universidade do Porto, Rua Dr. Roberto Frias, $4004200-465$ Porto, Portugal
}

Lucas da Silva

FEUP, Faculdade de Engenharia da Universidade do Porto, Rua Dr. Roberto Frias, s/n 4200-465 Porto, Portugal

Tiago Bento

IST, Instituto Superior Técnico, Universidade de Lisboa, Av. Rovisco Pais, 1049-001 Lisboa, Portugal

\begin{abstract}
Aeronautical structures have been assembled for decades using a wide variety of welding and joining techniques. Over the last 15-20 years significant developments in joining techniques have occurred.

Aluminium alloys have been the main traditional materials in civil aeronautical industry for the fuselage and structural parts. In order to reduce weight, improving fuel efficiency, there is the need to develop innovative solutions to join aluminium components in a single lap joint (SLJ) configuration with higher strength to weight ratio than riveting and fastening. In this work, a combination of the friction stir welding (FSW) and adhesive bonding (AB) processes is presented. Quasi-static mechanical properties, fatigue behaviour and other properties of the friction stir weld-bonding joints were assessed and compared with adhesive only and friction stir welded only joints.

The development of this new joining technology, combining FSW with AB, resulting in friction stir weld-bonding, aims to incorporate properties and characteristics of both joining technologies, as well as improving damage tolerance.

The present research involved the production of two types of overlap joints - FSW and hybrid friction stir weld-bonding. The main objective of this study is to compare the different joining technologies in lap joint configuration and evaluate the influence of different parameters on the mechanical behavior of the joints.

The hybrid joints present higher strength, ductility and hardness, with the highest joint efficiency achieved in the hybrid joint produced with $450 \mathrm{kgf}$. These findings lead to the conclusion that - hybridization process confers a joint efficiency improvement between $20-30 \%$ in most cases.
\end{abstract}

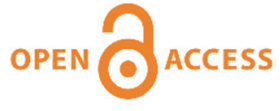

Citation: Maciel, R., Infante, V., Braga, D., Moreira, P.M.G.P., da Silva, Lucas, Bento, Tiago, Title title title, Frattura ed Integrità Strutturale, 48 (2019) 269-285.

Received: 14.09 .2018

Accepted: 05.12.2018

Published: 01.04.2019

Copyright: (C) 2019 This is an open access article under the terms of the CC-BY 4.0, which permits unrestricted use, distribution, and reproduction in any medium, provided the original author and source are credited. 
KEYWORDS. Friction stir welding, adhesive bonding, aluminium alloys, friction stir weld-bonding, mechanical behavior.

\section{INTRODUCTION}

A combination of regulatory requirements [1] and market demand [2,3] have pushed for continuous improvements in energy efficiency and performance in transport solutions. Weight reduction through the use of new lightweight alloys and new structural designs is a way to achieve these goals [3]. In order to implement lighter materials and innovative structural designs new manufacturing processes are required.

The aeronautical industry has been shy of welding processes in primary structures due to the related loss of mechanical properties from large heat inputs, weld quality control (process reliability) and the impossibility of welding precipitated hardened alloys (e.g. AA2024 aluminum alloy), in which cracks tend to form from the arc welding process. Solid state welding mitigates some of these concerns, as lower heat inputs result in improved mechanical performance and easier process control improves process reliability.

\section{Friction stir welding (FSW)}

FSW is a revolutionary joining method that allowed the welding of previously unwieldable alloys with excellent characteristics and has an enormous potential for application in a large array of industries. Friction stir welding has shown to produce sound quality, high performing joints making it the most appealing welding technology for aeronautical structures [4]. In its most basic form, FSW is performed with a tool composed of shoulder and pin, fractioning and mixing the material to weld. The tool is insert while in rotation into the pieces to be welded and transverses along the weld line, as shown in Fig. 1. The shoulder is mainly responsible for providing heat from friction on to the sheets or plates to be welded, while the pin's main job is mixing the materials to be joined.

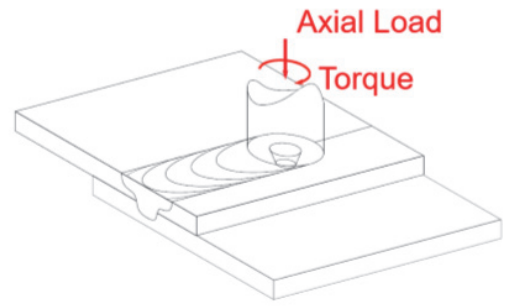

a)

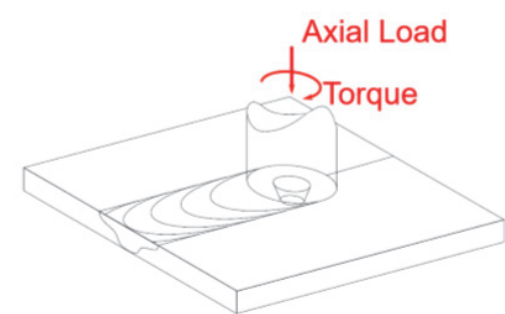

b)

Figure 1: Principle of the FSW process [5]: a) butt-joint configuration; b) overlap configuration (SLJ)

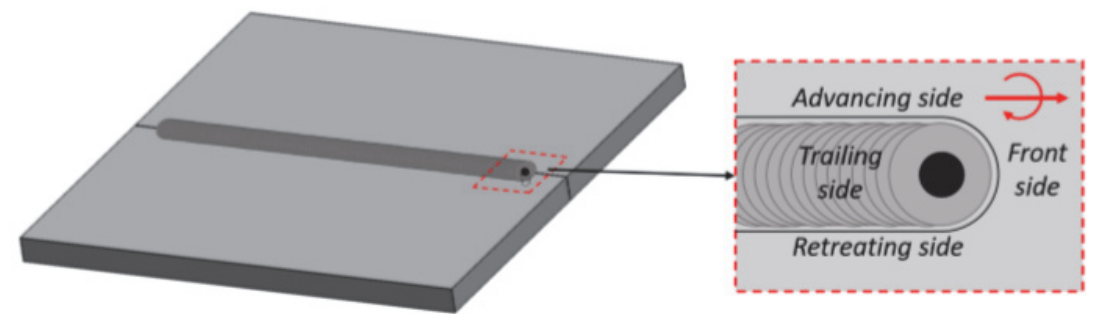

Figure 2: Schematic of a butt-joint weld and correspondent keyhole cross-section [7].

The process starts with and initial plunge of the tool into the work piece at a controlled rate, followed by a pre-heating stage called "dwell time". Preheating the material softens it along the joint line. When the suitable thermo-mechanical conditions are established, relative transverse movement, between the plates and the tool, starts, maintaining the rotation of the tool (welding phase). After welding, the tool is extracted from the plate leaving behind a characteristic keyhole, Fig. 2. 
The combination of heat and resultant material softening and recrystallization along with material flow during the process result in a modified metallographic structure in the joint cross-section. The resultant material zones have different physical and mechanical properties. Generally, these areas can be subdivided in 4 zones, as shown in Fig. 3. These are, the base material (BM) where heating is not sufficient to cause metallographic changes and the material keeps the original morphology, heat affected zone (HAZ) where heating is sufficient to cause softening, the thermo-mechanically affected zone (TMAZ) is softened and material plastic flow is noticeable here by the elongated and reoriented grains and in the center of the weld is the recrystallization zone, usually called weld nugget (WN), where the combination of heating and mixing of the tool causes grain breakage resulting in small equiaxed grains[8].

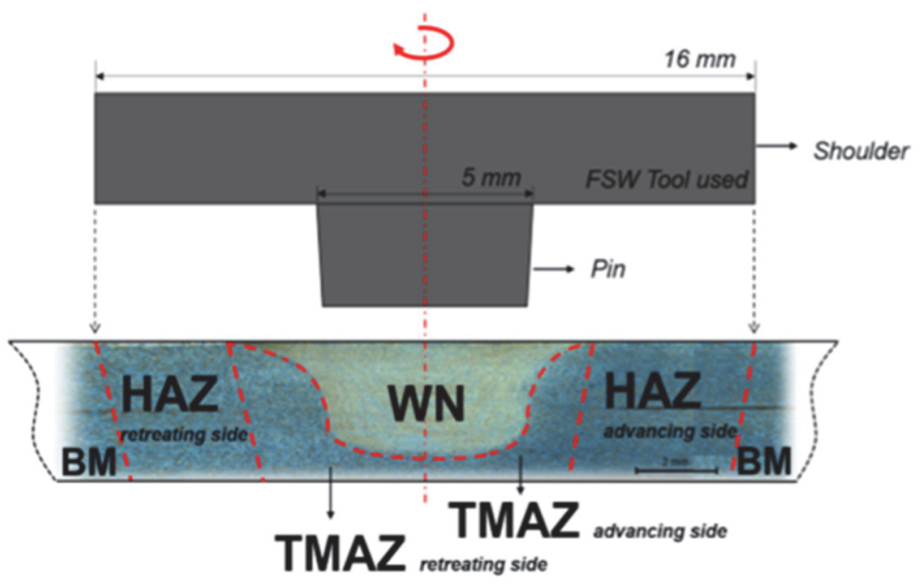

Figure 3: Resulting weld zones from FSW drawn on microscopic analysis image

Even though friction stir welding presents several advantages over other welding techniques when joining aluminium alloys, it also presents its share of challenges. For example, in the case of overlap configuration joints, which are very common in structural design, the presence of a hook defect, Fig. 4, reduces the static and fatigue strength as this defect acts like a crack initiation point. In certain alloys, the question of chemical corrosion is also a factor requiring good sealant measures to avoid degradation [9].

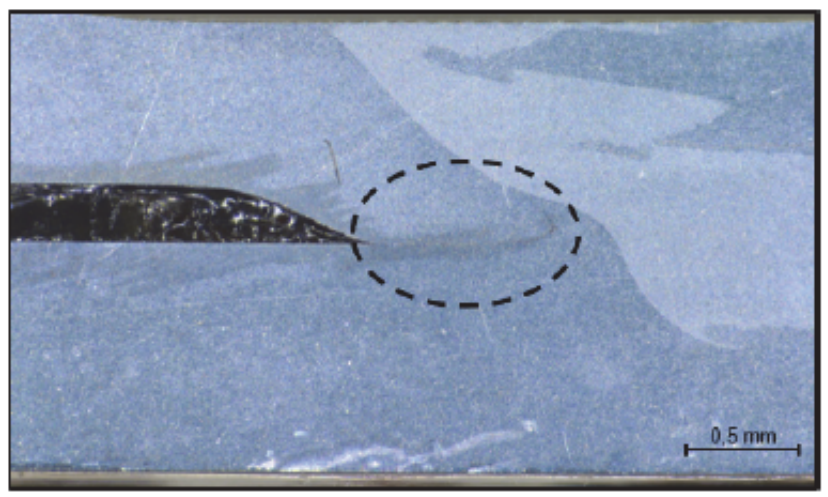

Figure 4: Hook defect in overlap configuration.

The heat generation and plastic deformation resultant from the FSW process causes the softening of the weld center line $[5,8]$. This FSW induced softening in precipitate hardened aluminium-magnesium-silicon alloys, as well as the typical W shape hardness profile.

A considerable database of tensile tests is already available in literature. In Moreira et al. [10] a $68.5 \%$ effectiveness( ratio of joints strength over bas material ultimate tensile strength) was obtained in AA6082-T6 welds. Braga in [5] compared the stress vs strain curves between the various material sections in FSW and base material AA6082-T6 aluminum alloy, using digital image correlation (DIC). In addiction, from [11] another tensile study for the same material was conducted, Fig. 5. 


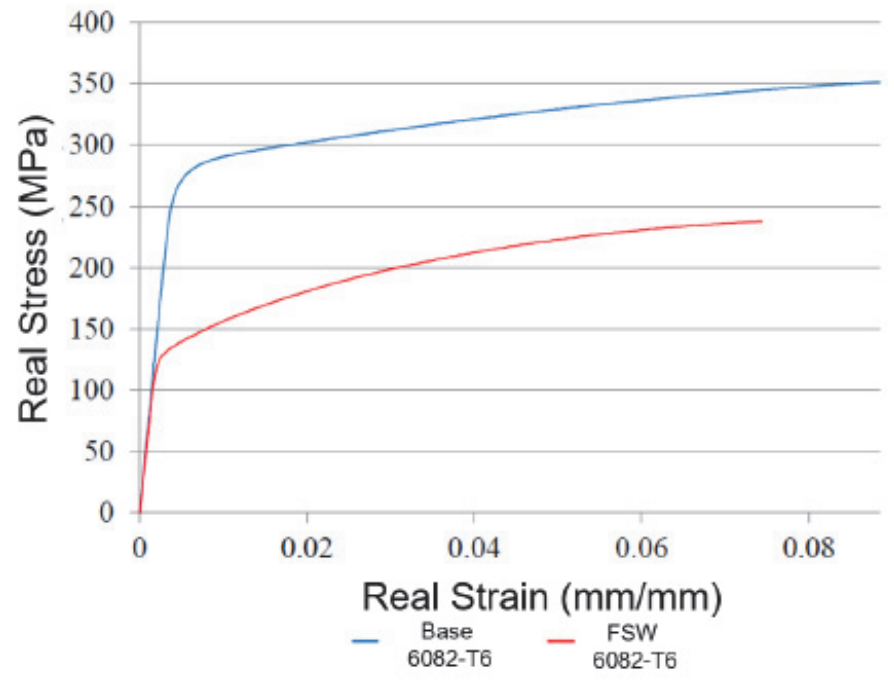

Figure 5: Base AA6082-T6 and FSW real stress vs. real strain curve [11]

In literature it is common for the welded joint to be classified according to its efficiency. The efficiency of a joint, Eqn. 1, is the ratio between the ultimate tensile strength of the welded joint and the ultimate tensile strength of base material:

$$
\text { Efficiency }=\frac{\sigma_{U T S F S W}}{\sigma_{U T S B M}}
$$

\section{Adhesive bonding $(A B)$}

Another technology, which despite having a longer history has received much development and research interest in the recent past for its light weighting potential is adhesive bonding (AB). Recent research in this field has focused on the adhesive properties and applications at high and low temperatures [11], fracture characterization [12], development and validation of numeric simulation tools [13, 14], self-healing and thermally expandable particles in adhesive joints [15], application cases [16, 17] as well as many other topics. As adhesive bonding, results in continuous bonds, the load distributions are more even and stress concentrations are avoided, improving the performance of the joints. Given the physical bonding mechanism, adhesive bonds have the benefit of being able to join dissimilar or difficult to weld materials. To guarantee sound quality joints, adhesive bonding requires special surface preparation to guarantee intimate bonding between adhesive and substrate surface. In addition, the environmental conditions during the curing process are critical to the joint quality, since even small surface contamination can cause up to $27 \%$ reduced strength [18].

Damage tolerance principles have favored hybrid joining technologies, which include two or more different joining techniques. Adhesive bonding (AB) has been a recurrently employed technique in this hybrid joining methods due to its manufacturing advantages, favorable joint properties as well as its flexibility.

The simplest and most used hybrid method is the combination between mechanical fastening and adhesive bonding [19, 20]. One of the earliest applications of assembly bonding was in the aluminium alloy fuselage panel joints of the Fokker F28, and later also in the Fokker 100, as well. The longitudinal splices of these aircraft, between adhesive-bonded fuselage panels were bonded with a room temperature-curing epoxy paste adhesive in assembly, cured and subsequently drilled and riveted. The effect of the assembly bonding of this critical joint is a dramatic improvement in fatigue life between $10 \%$ and $20 \%$, and a significant reduction of weight and manufacturing costs [21].

Moroni et al. in [22] studied hybrid single lap joints using resistance spot welding, riveting, clinching and self-piercing riveting in conjunction with adhesive bonding. The joints were tested for static strength, stiffness and energy absorption and were compared to only bonded and only mechanically joined or welded joints. The conclusions taken from this experimental study were that weld-bonded joints presented generally an increased stiffness strength and energy absorption when compared with spot welded joints, and that the contribution of the adhesive bonding was more evident in hybrid-fastened joints than in weld-bonded joints. This study also showed that based on the application requirements it was possible to "tailor" the joint with this hybrid joining techniques. 
When discussing weld-bonding methods, two distinct methodologies exist, "flow-in" and "weld-through". The "flow-in" method is highly laborious and as such not suitable for mass production. As such, an alternative approach was developed where the adhesive bonding was performed first followed by the welding procedure. This approach is called the "weldthrough" method. Both techniques are schematically presented in Fig. 6.

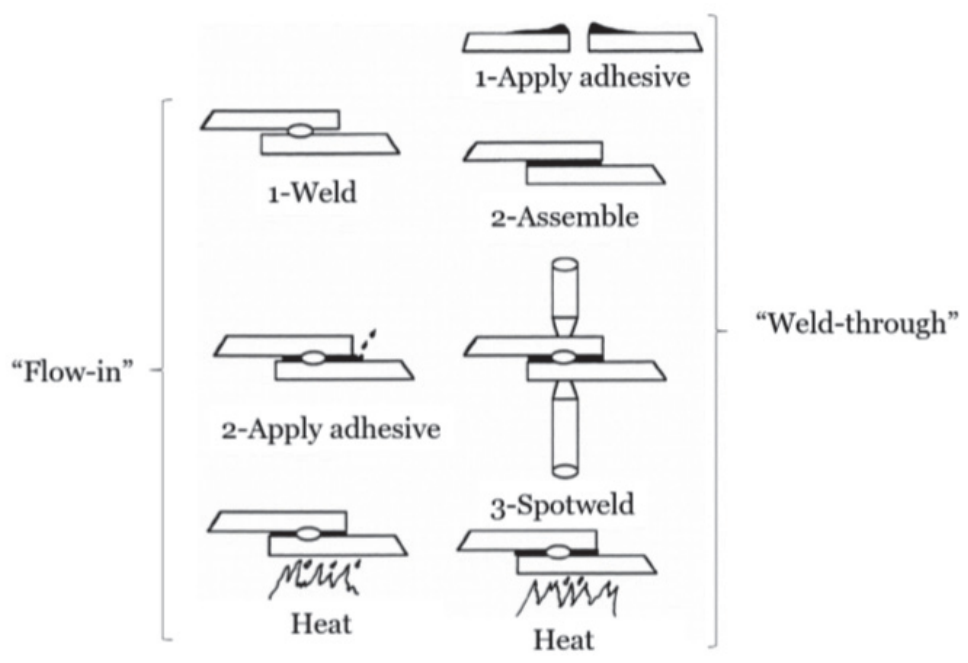

Figure 6: Weld-bonding in flow-in method and weld-through technique [23]

\section{EXPERIMENTAL DETAILS}

A s mentioned above, when discussing weld-bonding methods, two distinct methodologies exist, "flow-in" and "weld-through". The latter was chosen to be adopted in the development of friction stir weld-bonding, as the former would limit the choice of structural adhesive by viscosity and especially because a "weld-through" method as mentioned previously in the literature review presents various advantages concerning industrialization.

Single lap joints were made from $2.0 \mathrm{~mm}$ thick AA6082 - T6. Plates of 300x150x2 mm were used to produce single lap joints. The chemical composition of this alloy, according to the supplier provided material data sheet is presented in Tab. 1 and relevant mechanical properties are shown in Tab. 2.

\begin{tabular}{ccccccccccc}
\hline $\mathrm{Mn}$ & $\mathrm{Fe}$ & $\mathrm{Mg}$ & $\mathrm{Si}$ & $\mathrm{Cu}$ & $\mathrm{Zn}$ & $\mathrm{Ti}$ & $\mathrm{Cr}$ & $\begin{array}{c}\text { Others } \\
(\text { Total })\end{array}$ & $\mathrm{Al}$ \\
$0.40-1.00$ & 0.50 & $0.60-1.20$ & $0.70-1.30$ & 0.10 & 0.20 & 0.10 & 0.25 & 0.10 & Balance \\
\hline
\end{tabular}

Table 1: Chemical composition of AA6082-T6 (\% mass) [24].

\begin{tabular}{ccccc}
\hline $\begin{array}{c}\text { Density } \\
\left(\mathrm{kg} / \mathrm{m}^{3}\right)\end{array}$ & $\begin{array}{c}\text { Vickers } \\
\text { Hardness }\end{array}$ & $\begin{array}{c}\text { Ultimate Tensile } \\
\text { Strength }(\mathrm{MPa})\end{array}$ & $\begin{array}{c}\text { Yield Tensile } \\
\text { Strength }(\mathrm{MPa})\end{array}$ & $\begin{array}{c}\text { Elongation at Break } \\
(\%)\end{array}$ \\
2700 & 95 & 290 & 250 & 10 \\
\hline
\end{tabular}

Table 2: Mechanical Properties of AA6082-T6 [24]

The adhesive chosen was the Araldite 420 from Huntsman ${ }^{\circledR}$ (Salt Lake City, UT, USA). This adhesive is a two part epoxy (thermoset) capable of cure at room temperature, but temperature will accelerate the curing process and improve its strength. This adhesive was chosen due to its good mechanical strength and toughness, but especially due to its resistance to high temperature, which is required due to the high temperatures during welding [26]. Tab. 3 summarizes the mechanical 
properties of the structural adhesive, with curing temperature. These joints were then left to fully cure at room temperature for over a week achieving maximum room temperature cure.

\begin{tabular}{ccccccc}
\hline $\begin{array}{c}\text { Cure } \\
\text { temperature }\end{array}$ & $\begin{array}{c}E \\
(\mathrm{GPa})\end{array}$ & $\begin{array}{c}G \\
(\mathrm{MPa})\end{array}$ & $\begin{array}{c}\sigma_{u} \\
(\mathrm{MPa})\end{array}$ & $\begin{array}{c}\tau_{u} \\
(\mathrm{MPa})\end{array}$ & $\begin{array}{c}G_{I}^{c} \\
(\mathrm{~N} / \mathrm{mm})\end{array}$ & $\begin{array}{c}G^{c}{ }^{I I} \\
(\mathrm{~N} / \mathrm{mm})\end{array}$ \\
$\begin{array}{c}\text { Room } \\
\text { Temperature }\end{array}$ & 1.57 & 600 & 30 & 22.5 & 3 & 6.5 \\
$120^{\circ} \mathrm{C}$ & 1.73 & 665 & 40 & 28 & 3 & 6.5 \\
\hline
\end{tabular}

Table 3: Summary of Araldite 420 mechanical properties

Unlike in [9], the $3 \mathrm{M} \circledast \mathrm{AC}-130$ was used as surface pre-treatment. This product is an anodization replacement surface preparation product for the aeronautical industry and was used in this experimental procedure due to the very large joints to be manufactured. In case of actual application where the joints have very large dimensions as in the case of longitudinal fuselage joints, it is not possible to use PAA, phosphoric acid anodization [5].

The Fig. 7 shows the resultant layer of the AC-130 surface preparation process on an aluminium surface. Successful bonding requires thorough deoxidation and preparation of the metal surface. AC-130 may be applied by brush, spray or immersion, followed by room temperature drying stage.

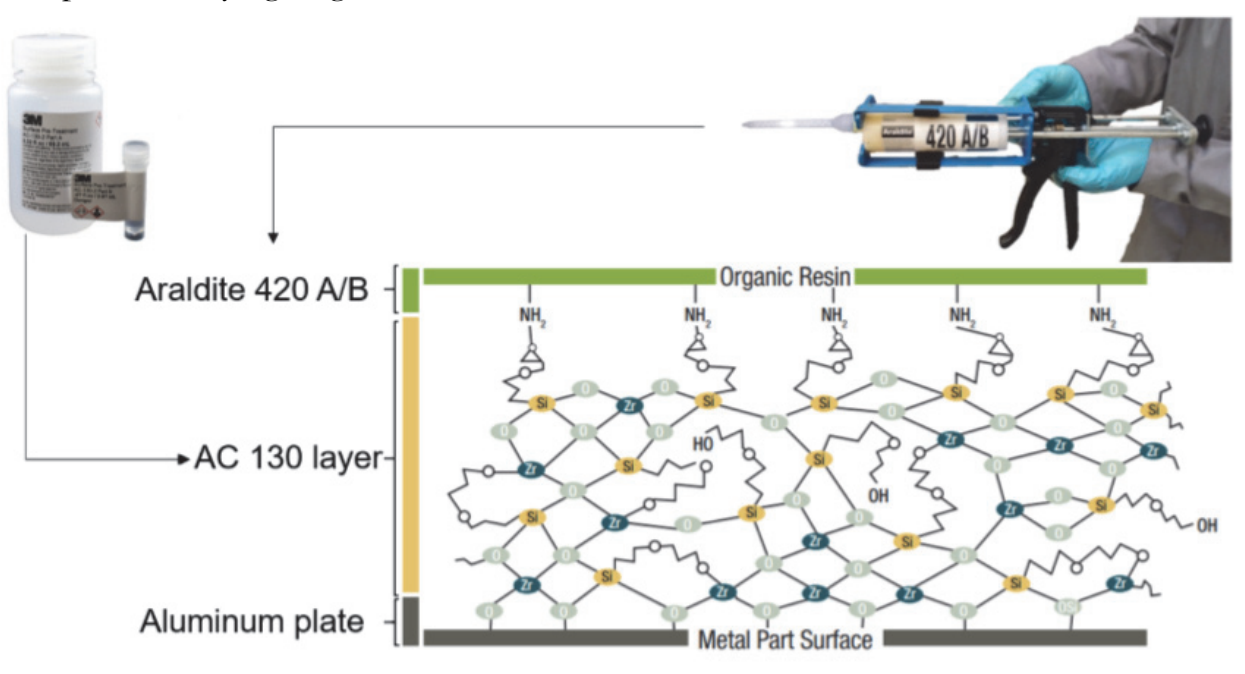

Figure 7: 3M $\mathrm{M}^{\mathrm{TM}} \mathrm{AC}-130$ (left) and Araldite $420 \mathrm{~A} / \mathrm{B}$ (right) and how their layers are organized, adapted from [25]

The FS Weld-bonded joints were made with an overlap of $40 \mathrm{~mm}$ and $20 \mathrm{~mm}$, with an adhesive thickness of $0.2 \mathrm{~mm}$, as show in Fig. 8. The adhesive thickness was guaranteed with calibrated steel spacers. A 40 mm overlap width is significantly smaller than current fastened joint designs of aeronautical fuselages, such as the case of longitudinal fuselage joints, [21] leading to weight savings.

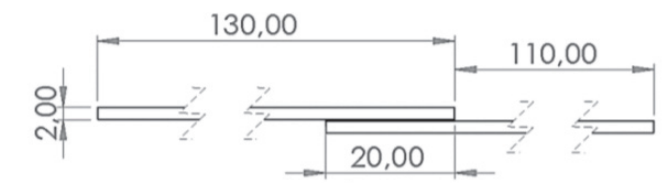

a)

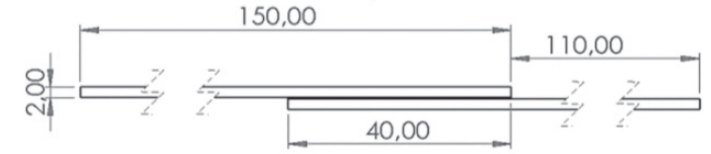

b)

Figure 8: Hybrid overlap joints cross section: a) $20 \mathrm{~mm}$ overlap; b) $40 \mathrm{~mm}$ overlap 
The application of the adhesive on the SLJ joint, is made on the bottom plate through a mixing tip with the aid of an application gun, as shown in Fig. 9.

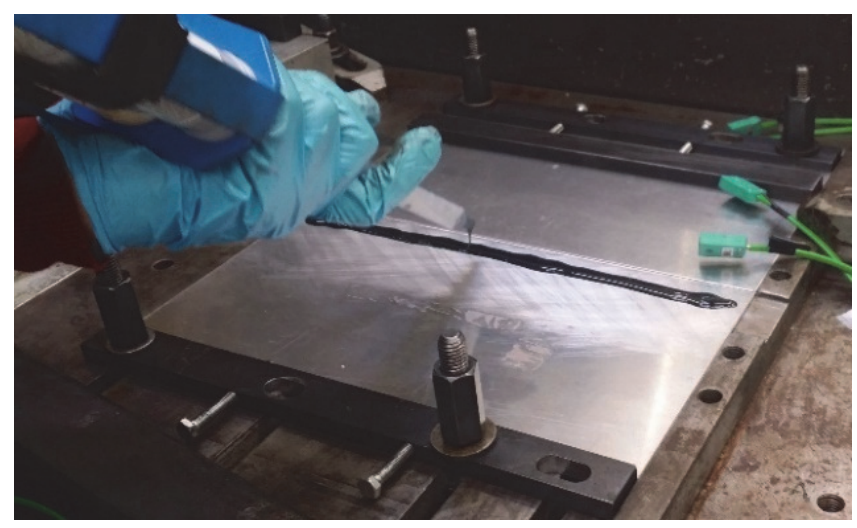

Figure 9: Adhesive application

The welds were performed on a dedicated FSW ESAB® (Gothenburg, Sweden) LEGIO 3UL numerical control machine. The machine is capable of welding both in displacement control, as well as load control. The machine integrates a cooling system for the welding tool.

A patented modular concept of FSW tool composed by three main components; body, shoulder and probe, was used to produce the joints in this study [9]. A threaded cylindrical shaped probe with $5 \mathrm{~mm}$ diameter was used in this FSW tool (see Fig. 10). The probe was mounted on a $16 \mathrm{~mm}$ diameter shoulder. The probe length was set to about $3 \mathrm{~mm}$ in order to promote an optimal mixture in the stirring zone since the overlap height would be about $4 \mathrm{~mm}$ total. Specimens restraining during welding was done at a distance of $10 \mathrm{~mm}$ towards the weld line in both sides of the weld [28].

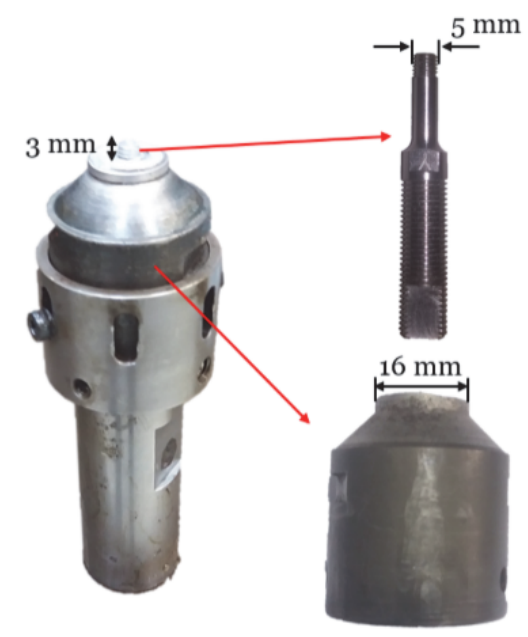

Figure 10: FSW tool used

The experimental procedure is composed by the following steps:

1. Surface treatment

2. Clamping process

3. Adhesive layering

4. FSW process

5. Curing process

As noted in the literature, a strong horizontal and vertical clamping forces are fundamental not only to prevent distortion and undesired movement of the plates but also to reduce the magnitude of residual stresses [29].

A clamping apparatus was developed in order to assure the correct fixation of the workpieces and spacers to assure consistent joint manufacturing, as shown in Fig. 11. 


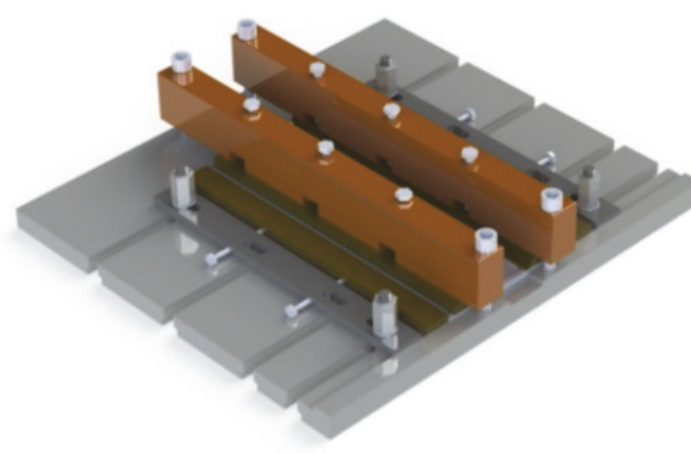

a)

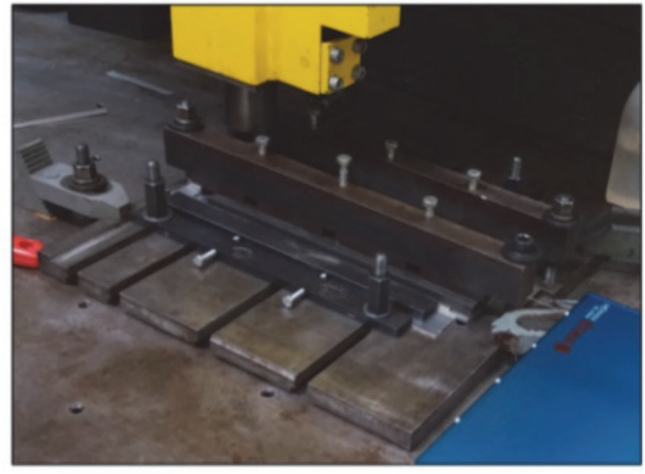

b)

Figure 11: Fixation system: a) CAD model; b) laboratory set-up

The FSW and FS Weld-bonded parameters used in this study were selected from a combination of trial and error and previous experience in manufacturing FSW lap joints. Along with the set of FSW process parameters listed in Tab. 4, the vertical force was varied.

\begin{tabular}{cc}
\hline Parameter & Value \\
FSW control & Vertical force \\
Rotation direction & $\mathrm{CW}$ \\
Plunge speed & $0.1 \mathrm{~mm} / \mathrm{sec}$ \\
Dwell time & $6 \mathrm{~s}$ \\
Tilt angle & $0^{\circ}$ \\
Welding speed & $200 \mathrm{~mm} / \mathrm{min}$ \\
Rotational speed & $1000 \mathrm{rpm}$ \\
Downward force & $400 / 425 / 450 / 500 / 550 \mathrm{kgf}$ \\
\hline
\end{tabular}

Table 4: Parameters used to perform all joints produced

The temperature spike resultant from the welding process assists the curing process, with the remaining cure occurring at room temperature. The total curing of the adhesive up to full strength was more than 7 days, according to the supplier data sheet. Tab. 5 lists the parameter combinations studied in this work.

\begin{tabular}{ccccc}
\hline Joint tag & $\begin{array}{c}\text { Plunging } \\
\text { force [kgf] }\end{array}$ & $\begin{array}{c}\text { Rotational } \\
\text { speed [rpm] }\end{array}$ & $\begin{array}{c}\text { Welding } \\
\text { speed [mm/min] }\end{array}$ & $\begin{array}{c}\text { Overlap } \\
{[\mathrm{mm}]}\end{array}$ \\
FSW_400 - 1 & 400 & 1000 & 200 & 40 \\
FSW_425 - 1 & 425 & 1000 & 200 & 20 \\
FSW_450 - 1 & 450 & 1000 & 200 & 40 \\
FSW_500-1 & 500 & 1000 & 200 & 40 \\
FSW_550-1 & 550 & 1000 & 200 & 40 \\
Hyb_400-1 & 400 & 1000 & 200 & 40 \\
Hyb_400-2 & 400 & 1000 & 200 & 40 \\
Hyb_425-1 & 425 & 1000 & 200 & 20 \\
Hyb_425-2 & 425 & 1000 & 200 & 40 \\
Hyb_450-1 & 450 & 1000 & 200 & 40 \\
Hyb_450-2 & 450 & 1000 & 200 & 40 \\
Hyb_450-3 & 450 & 1000 & 200 & 40 \\
Hyb_500-1 & 500 & 1000 & 200 & 40 \\
Hyb_550-1 & 550 & 1000 & 200 & 40 \\
\hline
\end{tabular}

Table 5: Overlap joints produced 
After the joining process, the produced joints were cut into $25 \mathrm{~mm}$ wide specimens accordingly to the ASTM D1002 standard, as show in Fig. 12.

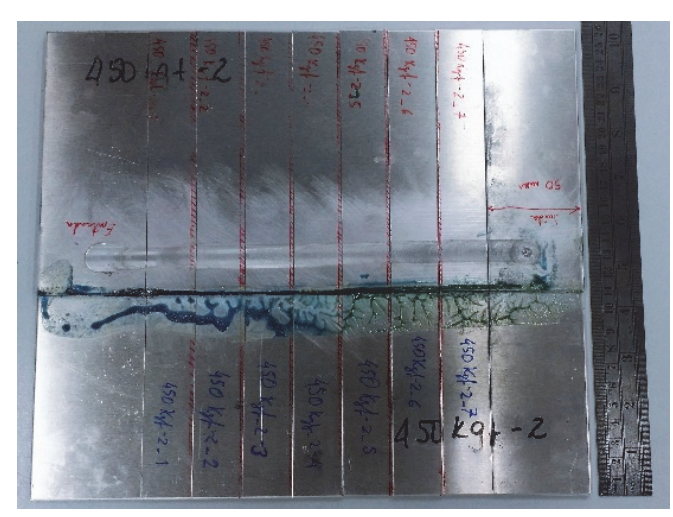

Figure 12: Specimens cut according do ASTM D1002

\section{Microscopy analysis}

To assess the quality of the joints and detect possible manufacturing defects, such as voids, cross section specimens were prepared for optical microscopy analysis. The microscope used for the posterior analysis was the LEICA DMS 300.

\section{Microhardness tests}

Microhardness profiles of the joints cross sections were made to assess the material transformations due to the welding process. This test aids the mechanical and micro structural characterization of the weld. The measurements were done in the specimens along two different lines, 0.8 and $1.6 \mathrm{~mm}$ from the bottom side of the overlap and one line at $0.5 \mathrm{~mm}$ from the top surface of the overlap with $0.3 \mathrm{~mm}$ indentation pitch.

The HMV micro hardness tester was the used machine, applying a load of $0.2 \mathrm{HV}(1,961 \mathrm{~N})$ during 10 seconds in each indentation. Only the specimen Hyb_400-1 and Hyb_450-1 were studied regarding micro hardness, as joints of more resistance.

\section{Tensile tests}

To determine the tensile mechanical proprieties of the hybrid welds, lap shear strength tests were performed on the ASTM D1002 standard specimens with $2 \mathrm{~mm}$ thickness as observed in Fig. 12. Each parameter set was tensile tested with three repetitions. Shims were used to mitigate the out of plane bending moment resultant from the overlap configuration.

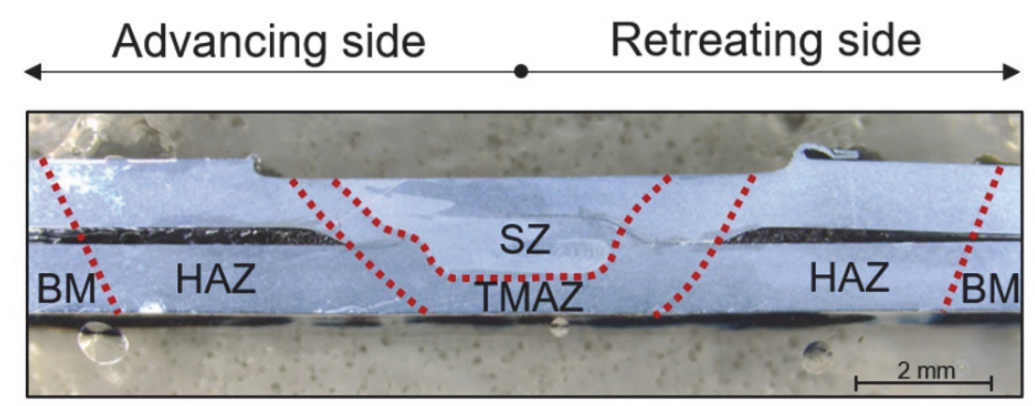

Figure 13: Overall macrostructure of AA6082-T6 hybrid overlap joints [7]

\section{EXPERIMENTAL RESULTS AND DISCUSSION}

\section{Microstructural evolution}

7 he mixed contribution of high temperatures and plastic deformation during the friction stir welding process leads to recrystallization, precipitate dissolution and coarsening of the aluminum in the stir affected zone. On the microscopic analysis performed with different magnifications, these effects could be observed and the zones 
identified. Each zone will have a different set of mechanical proprieties affecting the mechanical response of the entire joint, Fig. 13.

The macroscopic images obtained for joints manufactured with three different load conditions (400, 425 and $450 \mathrm{kgf})$ are presented in the Figs. 14, 15 and 16 below:

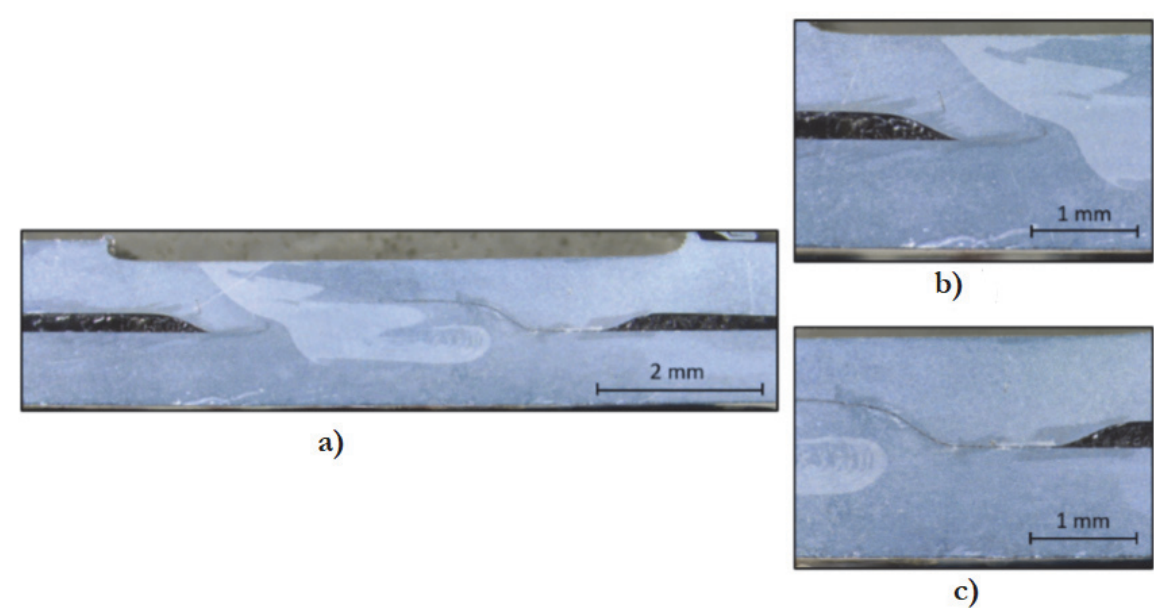

Figure 14: Hyb400-1: a) overall view; b) advancing side; c) retreating side

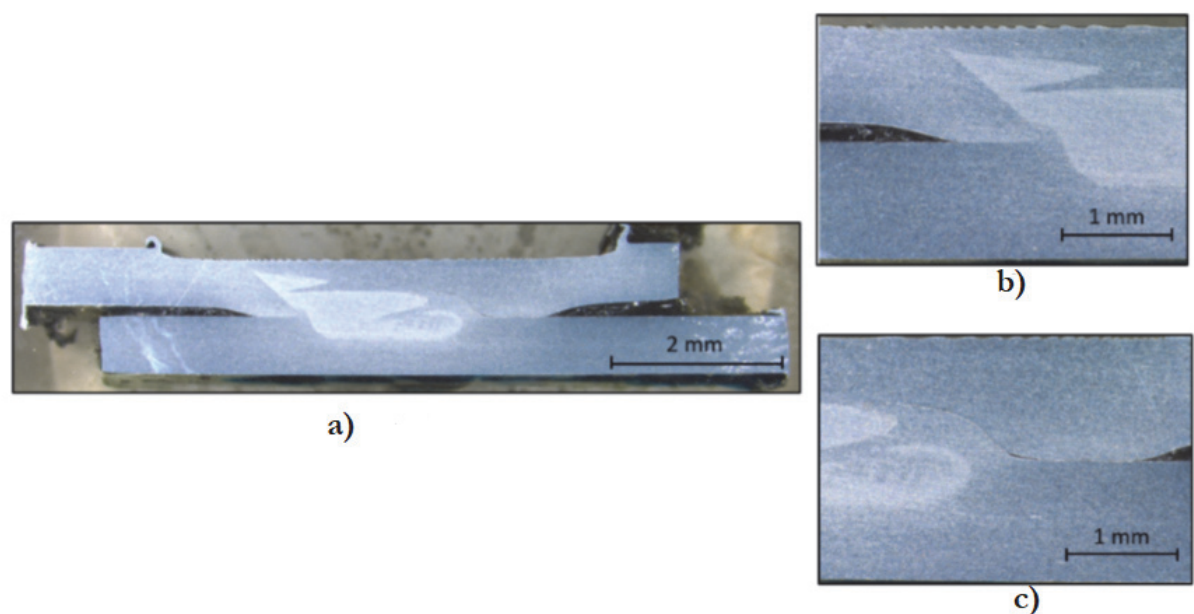

Figure 15: Hyb425-1: a) overall view; b) advancing side; c) retreating side

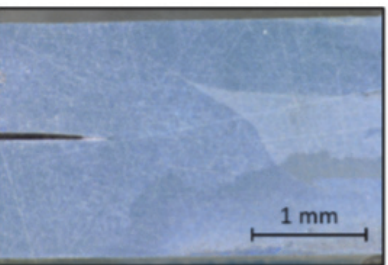

b)

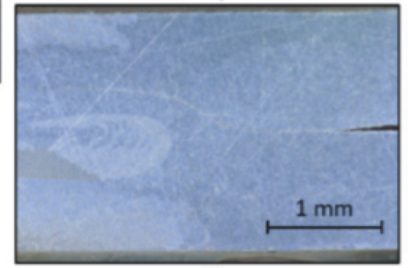

c)

Figure 16: Hyb450-1: a) overall view; b) advancing side; c) retreating side 
The macrostructures observed present a significant defect called hook defect. This phenomenon is a result of the upward flow of material generated in the advancing side, which at the same is time transported by the tool pin pushing up a zone of un-welded material and curving that particular section up. This is how the hook is generated. The grain orientation in this zone, boundary between SZ and TMAZ, suggest that unlike in the HAZ, there has been an upward motion of material provoked by the pin. Also, the hook shape suggest a sideward flow in the upper region caused by the tool shoulder. The size and intensity of the hook will therefore be dependent on these two motions, Fig. 17, and this defect reduces the effective thickness of the top sheet. This defect was shown to be present in all the manufactured joints in this experiment independently of the applied vertical load, figures $14 \mathrm{~b}), 15 \mathrm{~b})$ and $16 \mathrm{~b}$ ).

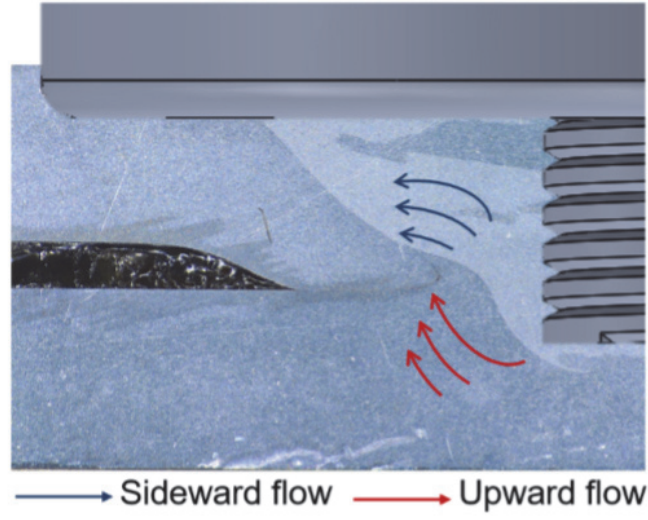

Figure 17: Schematic representation of hook defect formation mechanics.

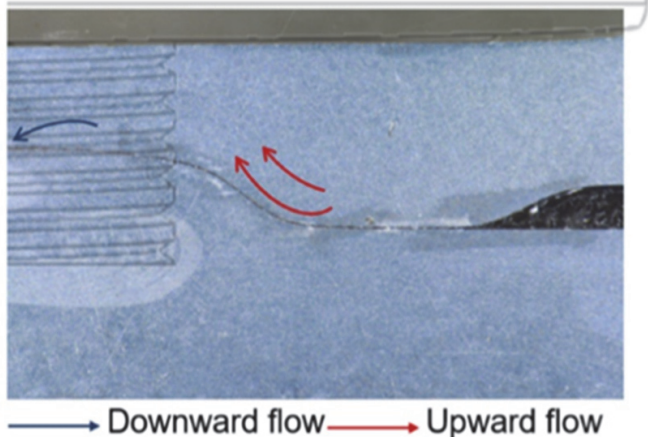

Figure 18: Schematic representation of cold lap defect formation mechanics.

Another visible defect is the cold lap defect, Figs. $14 \mathrm{c}$ ), 15c) and $16 \mathrm{c}$ ). This defect appears in the retreating side, and it is a consequence of the initial upward flow under shearing effect of the pin followed by a downward flow in order to fill the space at the bottom of the pin, Fig. 18. In all the welds manufactured this defect was quite significant and that is a result not only of the pin shearing effect but mainly due to the relatively high welding speed, $20 \mathrm{~cm} / \mathrm{min}$, which increases the pin cavity volume per tool rotation, which stimulates the downward flow to fill that gap.

Both defects mentioned above result in thinning of the SLJ joints and degradation of mechanical performance because they result in stress concentration areas.

However, as it may be observed in Figs. 14, 15 and 16, with an increase in vertical load applied by the tool (Fig. 14 - 400 kgf, Fig. 15 - $425 \mathrm{kgf}$, Fig. 16 - $450 \mathrm{kgf}$ ) there is a dampening of the defects, becoming less severe. This reduction of the defect size may be due to the higher forging force, that while maintaining welding speed and the rotational speed, constant, results in higher heat generation, which ends up allowing a better mixing of the materials. This causes the reduction of stress concentration that occurs at the tip of the hook, making the cold lap more favorable to crack generation. Therefore, the steering process was more efficient in case of Fig. 16 and suggests that the higher the load applied in the welding process the higher the joint strength will be. The adhesive layer is shown to be continuous in the cross section stopping at TMAZ, at both the advancing and retreating side. As shown in Maroni [22], this adhesive interlayer expected to increase the strength and ductility of the joint. Nevertheless, it was verified that despite the application of $0.2 \mathrm{~mm}$ calibrated metal strips to guarantee a uniform distribution of adhesive, there is a slight variation along the cross section which might induce some discrepancies in the laboratory.

\section{Microhardness analysis}

The tests were performed on hybrid joint samples manufactured with 400 kgf and 450 kgf, "Hyb_400-1" and "Hyb_450$1 "$. The results are presented in Figs. 19 and 20.

In at welding region, Fig. 19, softening is observed around the weld nugget (WN) as reported in literature. In [8] it is suggested this softening is caused by coarsening and dissolution of strengthening precipitates due to the thermal cycles the welds are subjected in the welding process. The lowest hardness value is located away from the center line, in the WN limits, about $5 \mathrm{~mm}$ for the upper measurements, in red, and $2.5 \mathrm{~mm}$ for the lower ones, the blue and the green, which is equivalent to the pin limits. In this region of minimum hardness only low density rod-shaped precipitates are present [8] which provokes the hardness to be reduced. In tensile tests this minimum hardness zone is where the fracture is located. The 
precipitates tend to disappear inwards, in the center line direction and the hardness increases. Moving outwards, the density of rod-shaped precipitates increases gradually until base material proprieties are met, conform related in [8].

From Fig. 20 it is possible to conclude that the different loads applied by the tool have very little impact on the specimen microhardness distribution. However, the hardness values of the $400 \mathrm{kgf}$ tool force weld tend to be lower than the ones for the $450 \mathrm{kgf}$ which is another indication that the former might have lower fracture strength. This phenomena is explained in [10] by the loss of the T6 condition. In other words, during the welding process the temperature in the more central zones, such as the $\mathrm{SZ}$ and the $\mathrm{HAZ}$, exceed $200{ }^{\circ} \mathrm{C}$, causing the main strengthening precipitate, $\beta "{ }^{\prime \prime}-\mathrm{Mg}_{5} \mathrm{Si}_{6}$, to dissolve.
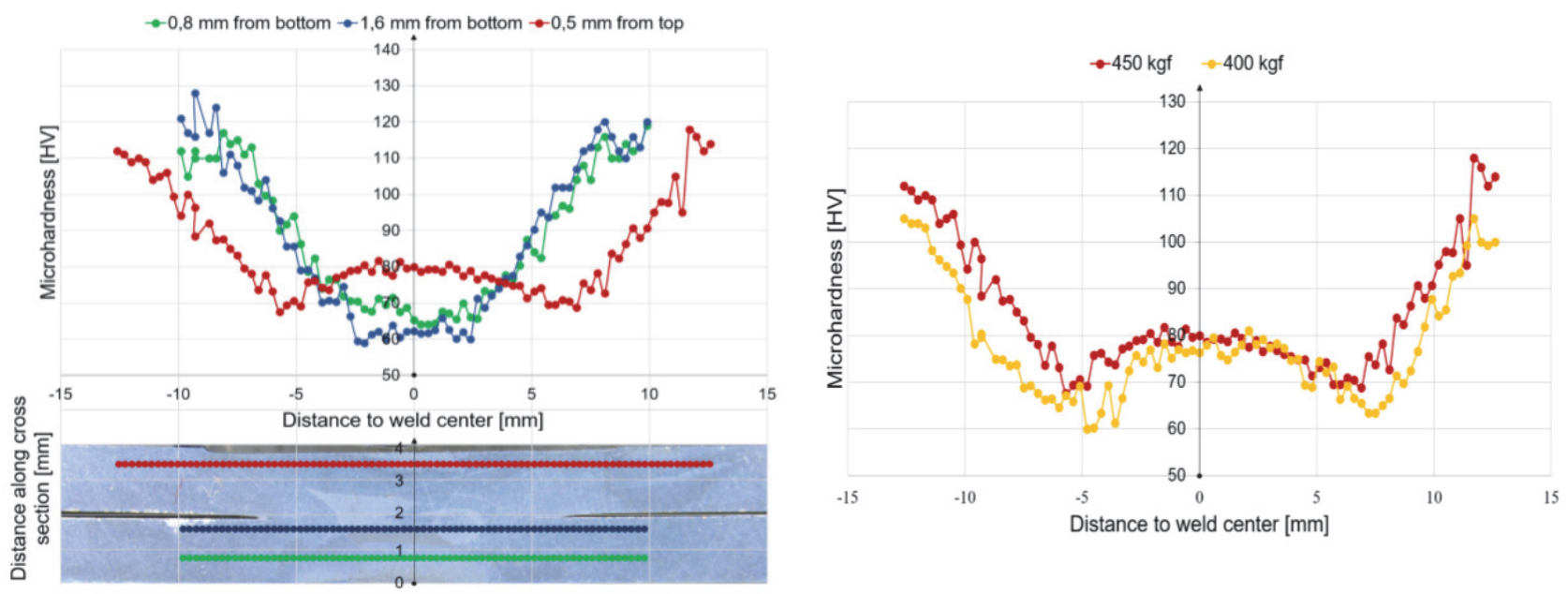

Figure 19: Microhardness curves of the "Hyb_450-1" cross section Figure 20: Microhardness curves of the $400 \mathrm{kgf}$ and $450 \mathrm{kgf}$

\section{Single lap shear tests}

Joints, FSW only and hybrid, subjected to quasi-static tensile loading showed two distinct failure modes, as in [27]:

- In the first fracture mode, mode I, the fracture originates in the retreating side of the weld, initiated in the cold lap defect and propagating in parallel to the top surface in the direction of the hook defect, Fig. 21.

- The second fracture mode, mode II, was present in the majority of the joints and was also the one verified in the numerical analysis, just like [5]. In this mode the fracture occurred in the advancing side of the weld, initiated in the hook defect and then propagated perpendicularly to the top surface, Fig. 22. In mode II, the force creates a sliding, or shear mode in direction perpendicular to the leading edge of the crack.
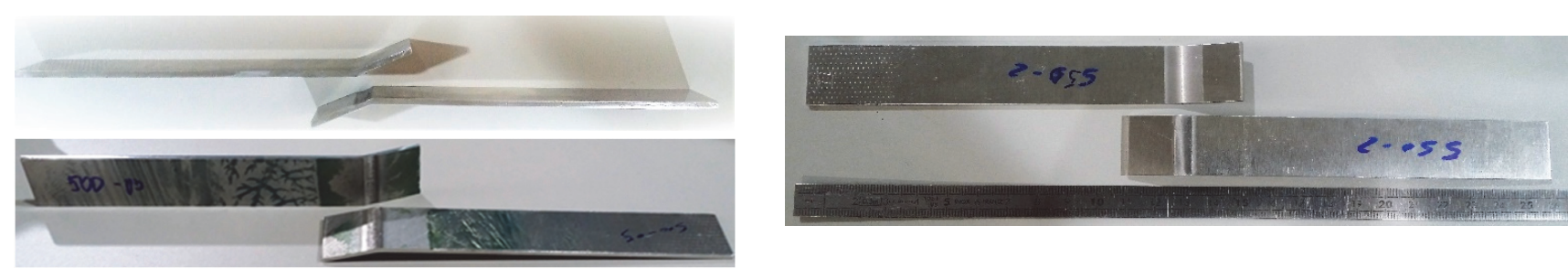

Figure 21: Different views of mode I failure in a joint
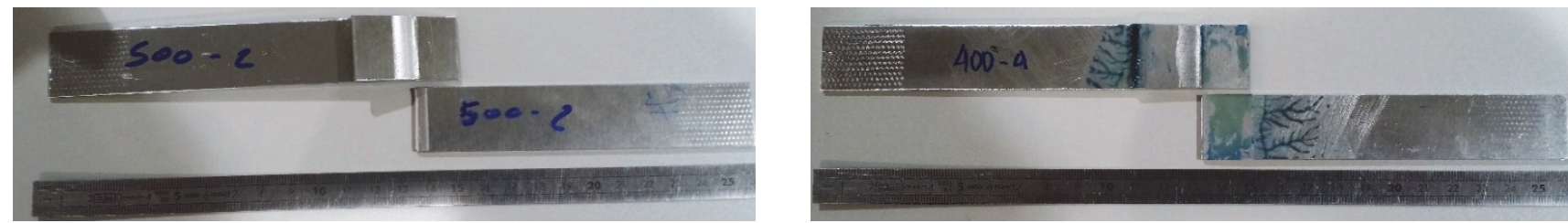

Figure 22: Different views of mode II failure in a joint

In the FSW-only joints a trend was observed in respect to the failure modes. As the downward force increased the fracture changed from mode II to mode I which was accompanied by an increase in joint strength. 
In the Hybrid joints that transition is not as linear and it was verified that when under mode I, the joints tended to fracture with lower applied force, since the adhesive is not as resistance to fracture under peal force as it is under pure shear force conditions. This result suggests that higher downward forces, over $500 \mathrm{kgf}$, tend to degrade the adhesion quality and the adhesive is not as effective under mode I conditions. So, for the hybrid joints, unlike the FSW-only ones, the preferred mode, with better performance, would be mode II.

\section{FSW joint}

In the Fig. 23 below the results for the specimens "FSW (400,450,400,550) - 1" are compared. All the parameters but the downward force was kept constant.

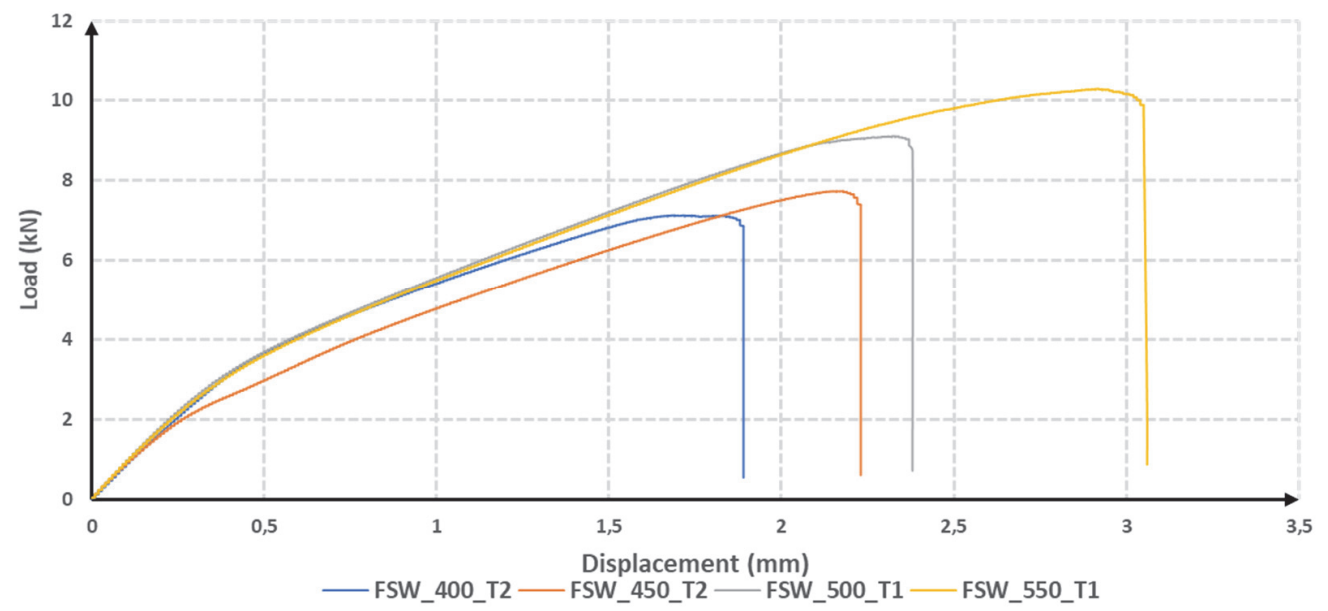

Figure 23: Load-displacement comparison of the FSW specimens

The average values of maximum load were calculated for all the different configurations, Tab. 6, to estimate the ultimate tensile strength (UTS), useding the Eqn. 1. Also the average ductility was accessed by measuring the maximum displacement in each case.

\begin{tabular}{cccccc}
\hline Joint tag & $\begin{array}{c}\text { Average } \\
\text { maximum load } \\
{[\mathrm{kN}]}\end{array}$ & $\begin{array}{c}\text { Maximum load } \\
\text { dispersion } \\
{[\mathrm{kN}]}\end{array}$ & $\begin{array}{c}\text { Average } \\
\text { maximum } \\
\text { displacement } \\
{[\mathrm{mm}]}\end{array}$ & $\begin{array}{c}\text { Maximum } \\
\text { displacement } \\
\text { dispersion } \\
{[\mathrm{mm}]}\end{array}$ & UTS [MPa] \\
FSW_400-1 & 7.21 & 0.10 & 1.88 & 0.02 & 144.2 \\
FSW_450-1 & 7.61 & 0.12 & 2.00 & 0.21 & 152.2 \\
FSW_500-1 & 8.84 & 0.16 & 2.35 & 0.17 & 176.8 \\
FSW_550-1 & 9.10 & 0.80 & 2.47 & 0.41 & 188.2 \\
\hline
\end{tabular}

Table 6: Details of the lap shear strength tests of the FSW joints

The dispersion of results was considerably small which, is an indicator of reliability of the tests performed. For the calculi of the dispersion was used standard deviation.

As observed in the figures and table above, the increase in downward force, is followed by an increase in joint strength in a simple FSW joint. This result confirms the indications that had already been put out by the microscopic and micro hardness analysis. The joint produced with the highest force displayed less evident defects, a more efficient steering and higher overall hardness. As a consequence, the "FSW550-1" is the joint that displays higher ultimate tensile strength and ductility.

The fracture in joints produced with 400, 450 and $500 \mathrm{kgf}$ initiated in the advancing side, hook defect, and propagated until the top aluminum sheet, mode of fracture II. Whereas in the joint produced with $550 \mathrm{kgf}$ it was initiated in the cold lap defect and propagated along the cross section until the hook defect, mode of fracture I, as show the Fig. 24. 


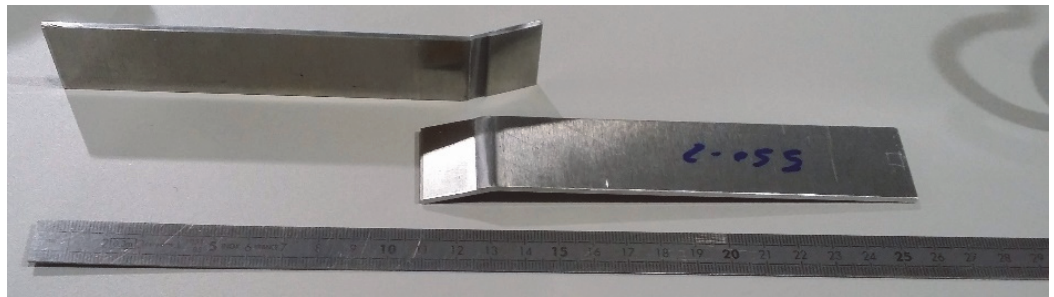

Figure 24: Fracture mode I in SLJ joints FSW_550-1 of with 550 kgf downward force

Hybrid joint $-F S W+A B$

In the Fig. 25 below the results for the specimens "Hyb (400,450,500,550) - 1" are compared. Here again, a representative curve was selected from the results. All the parameters but the downward force was kept constant.

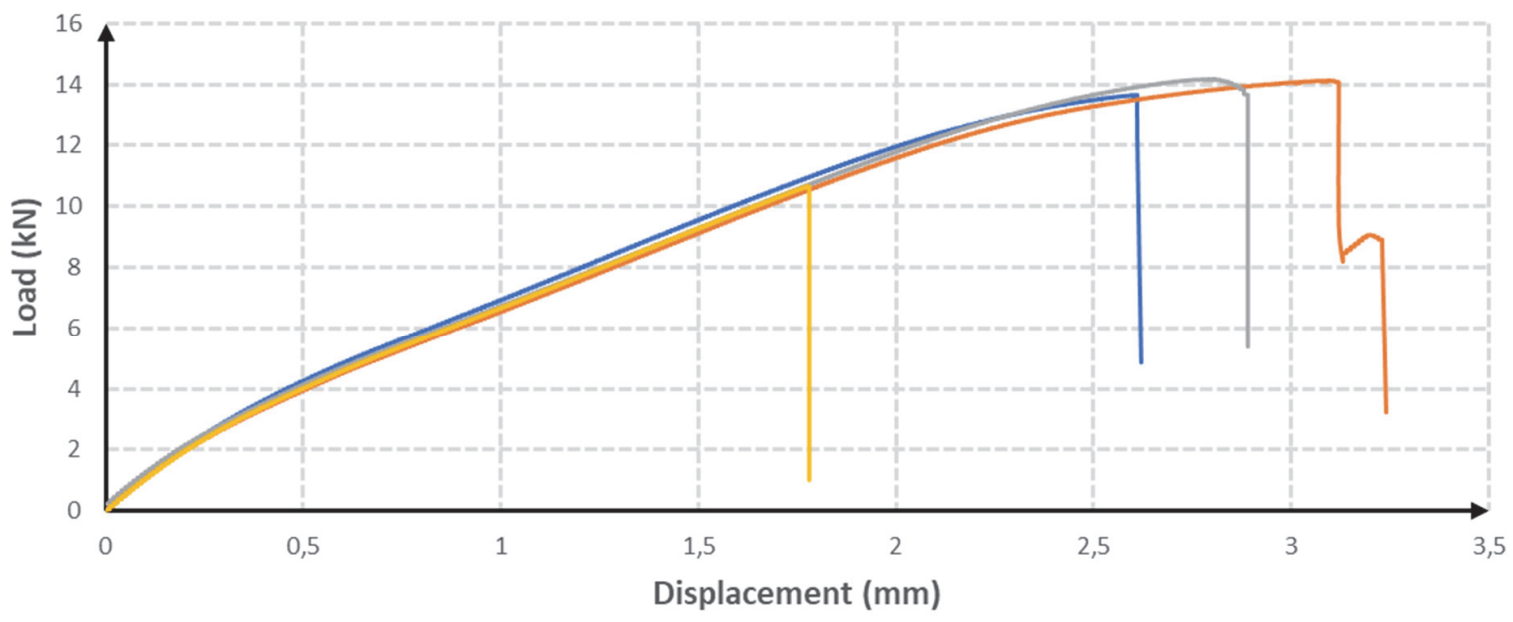

-Hyb_400_T4 - Hyb_450_T3 - Hyb_500_T3 - Hyb_550_T2

Figure 25: Load-displacement comparison of the Hybrid specimens:

The maximum displacement and maximum load averages is presented in Tab. 7.

\begin{tabular}{cccccc}
\hline Joint tag & $\begin{array}{c}\text { Average } \\
\text { maximum load } \\
{[\mathrm{kN}]}\end{array}$ & $\begin{array}{c}\text { Maximum } \\
\text { load dispersion } \\
{[\mathrm{kN}]}\end{array}$ & $\begin{array}{c}\text { Average } \\
\text { maximum } \\
\text { displacement } \\
{[\mathrm{mm}]}\end{array}$ & $\begin{array}{c}\text { Maximum } \\
\text { displacement } \\
\text { dispersion } \\
{[\mathrm{mm}]}\end{array}$ & UTS [MPa] \\
\hline Hyb_400-1 & 10.63 & 3.66 & 2.10 & 0.76 & 212.6 \\
Hyb_450-1 & 12.22 & 2.40 & 3.15 & 1.14 & 244.4 \\
Hyb_500-1 & 11.64 & 2.28 & 2.66 & 0.47 & 232.8 \\
Hyb_550-1 & 11.15 & 1.23 & 1.99 & 0.21 & 223.0 \\
\hline
\end{tabular}

Table 7: Details of the lap shear strength tests of the hybrid joints

The fracture in the hybrid SLJ joints occurred in mode II for lower downward shoulder forces applied, 400-450 kgf and with higher forces 500-550 kgf in mode I.

However, in the case of the hybrid joints, the increment in force is not followed by an improvement in joint performance. In the tensile tests it was verified that the rotation is more accentuated in joints manufactured with higher downward force, which is a consequence of the damping of the hook defect. This causes a higher rotation and consequently higher peel stress, making the adhesive less resistant to fracture.

The best results, both for fracture toughness and ductility are therefore obtained with an applied force of $450 \mathrm{kgf}$ which might be considered as an inflection point in joint performance maintaining all the other parameters constant. 
The maximum displacements achieved the case of the hybrid joints slightly increase in relation to the ones observed in the FSW only SLJ joints so the adhesive increases the ductile character of the joint.

When comparing the UTS of the joints produced with the base material is possible to obtain the joint efficiency. A base material specimen of the same material (AA6082-T6) and dimensions was measured to have $\sigma_{U T S}=331.4 \mathrm{MPa}$. So calculating the efficiency according to Eqn. 1 the results in Fig. 26 were obtained.

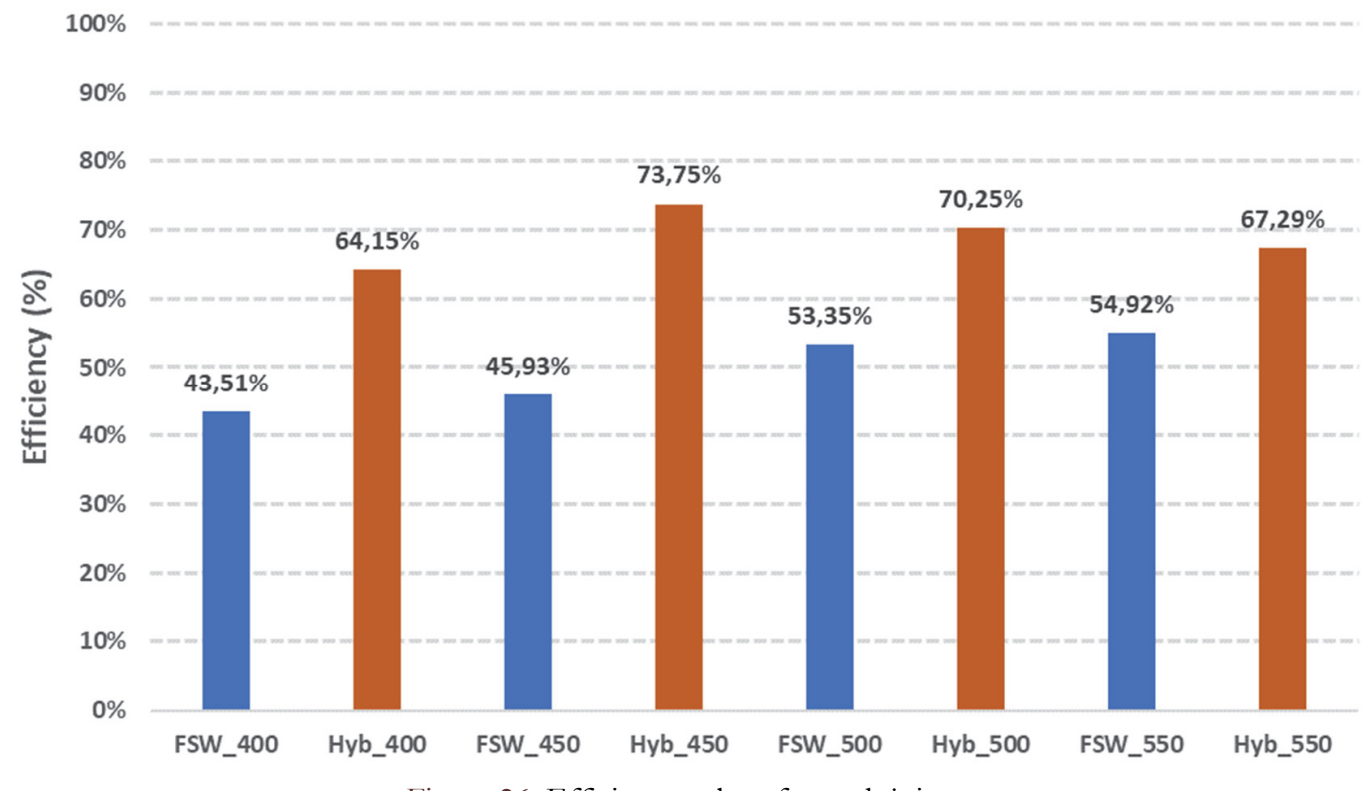

Figure 26: Efficiency values for each joint.

The hybrid joints present better overall results, and as already mentioned the best joint was efficiency achieved with the hybrid joint produced with $450 \mathrm{kgf}$. The average efficiency value in this case was $73.75 \%$, however in a particular specimen it reached the value of $85.21 \%$.

From the results of Fig. 26 it is possible to affirm that the hybridization process confers an improvement between 20 -30 \% in most cases. In the case of the $550 \mathrm{kgf}$ the improvement is less evident and above that value the adhesive should lose even more effectiveness in the joint.

\section{CONCLUSIONS}

he main purpose of this research study was to successfully manufacture FSW and hybrid friction stir weld-bonding single lap joints, using microscopy analysis, microhardness tests and lap shear strength tests to detect defects and evaluate the influence of different parameters on the mechanical behavior of the joints. The FSW and hybrid joints were benchmarked under static loading and classified according to its efficiency.

In the microstructures analysis, a significant defect called hook defect was observed. This defect was shown to be present in all the manufactured joints in this experiment independently of the applied vertical load. Another visible defect is the cold lap defect, was quite significant in all the welds manufactured. Both defects mentioned above result in thinning of SLJ joints and degradation of mechanical performance because they result in areas of stress concentration. However, as can be observed with an increase in vertical load applied by the tool (Fig. 14 - $400 \mathrm{kgf}$, Fig. 15 - $425 \mathrm{kgf}$, Fig. 16 - $450 \mathrm{kgf}$ ) there is a dampening of the defects, becoming less accentuated and smaller. The reason behind this is that with higher forging force, maintaining welding, $\omega$, and rotational, $v$, speeds constant, there is a higher heat generation, h, which ends up allowing a better mixing of the materials.

In the microhardness curves obtained of the hybrid joint cross section the softening is observed around the weld nugget (WN) as reported in literature. From Fig. 20 it is possible to conclude that the different loads applied by the tool have very little impact on the specimen microhardness distribution. However, the hardness values of the $400 \mathrm{kgf}$ tool force weld tend to be lower than the ones for the $450 \mathrm{kgf}$ which is another indication that the former might have lower fracture strength. 
In the SLJ tensile tests, the load was applied on the advancing side. In the FSW-only joints a trend was observed in respect to the failure modes. As the downward force increased the fracture changed from mode II to mode I which was accompanied by an increase in joint strength. In the Hybrid joints that transition is not as linear and it was verified that when under mode I, the joints tended to fracture with lower applied force, since the adhesive is not as resistance to fracture as it is under pure shear force. This result suggests that higher downward forces, over $500 \mathrm{kgf}$, tend to degrade the adhesion quality and the adhesive is not as effective under mode I conditions. So, for the hybrid joints, unlike the FSW-only ones, the preferred mode, with better performance, would be mode II.

The best results, both for fracture toughness and ductility are therefore obtained with an applied force of $450 \mathrm{kgf}$ which might be considered as an inflection point in joint performance maintaining all the other parameters constant.

The hybrid joints present better overall results, the best joint was efficiency achieved with the hybrid joint produced with $450 \mathrm{kgf}$. The average efficiency value in this case was $73.75 \%$, specimen it reached the value of $85.21 \%$. The from the results it is possible to affirm that the hybridization process confers an improvement between $20-30 \%$ in most cases.

\section{ACKNOWLEDGMENTS}

7 his work was supported by FCT, through IDMEC, under LAETA, project UID/EMS/50022/2019. Funding provided from NORTE-01-0145-FEDER-000022 SciTech - Science and Technology for Competitive and Sustainable Industries is acknowledged. The authors acknowledge the funding provided by FCT project PTDC/EME-EME/29340/2017 - DisFri.

\section{REFERENCES}

[1] European Commission (2009). Directive 2009/33/EC - Clean and energy-efficient road transport vehicles, pp. 5-12. Available at: https://eur-lex.europa.eu/legal-content/en/txt/pdf.

[2] Peeters, P. M., Middel, J. and Hoolhorst, A. (2005). Fuel efficiency of commercial aircraft. NLR-CR-2005-669, (November), pp. 1-37.

http://www.transportenvironment.org/sites/te/files/media/2005-12_nlr_aviation_fuel_efficiency.pdf.

[3] Reynolds, C. and Kandlikar, M. (2007). How hybrid-electric vehicles are different from conventional vehicles: The effect of weight and power on fuel consumption. Environmental Research Letters, 2(1). DOI: $10.1088 / 1748-9326 / 2 / 1 / 014003$.

[4] Braga D. F. O, Maciel R, Bergmann L., et al. (2018). Fatigue performance of hybrid overlap friction stir welding and adhesive bonding of an Al - Mg - Cu alloy. Fatigue Fract Eng Mater Struct, pp. 1-9. DOI: 10.1111/ffe.12933.

[5] Braga, D. F. O. (2018). Innovative structural joining for lightweight design. Submitted for the degree of Doctor of Philosophy in Leaders for Technical Industries of the MIT-Portugal Program. Faculty of Engineering of the University of Porto, Portugal.

[6] Marques, E. A. S. et al. (2014). Adhesive joints for low- and high-temperature use: An overview. Journal of Adhesion, 91(7), pp. 556-585. DOI: 10.1080/00218464.2014.943395.

[7] Bento, T. J. L. A. A. (2018). Smart Hybrid Friction Stir Welded Joints for Aerospace Design Applications. Submitted to obtain the Master of Science Degree in Aerospace Engineering. Higher Technical Institute of the University of Lisbon, Portugal.

[8] Mishra, R. S. and Ma, Z.Y. (2005). Friction stir welding and processing. Materials Science and Engineering: R: Reports, 50(1-2):1 - 78. issn 0927-796X. DOI: 10.1016/j.mser.2005.07.001.

[9] Braga, D. F. O. et al. (2015). Aluminum Friction Stir Weldbonding. Procedia Engineering, Elsevier B.V., 114, pp. 223231. DOI: 10.1016/j.proeng.2015.08.062.

[10] Moreira, P. M. G. P. et al. (2009). Mechanical and metallurgical characterization of friction stir welding joints of AA6061T6 with AA6082-T6, Materials and Design, 30(1), pp. 180-187. DOI: 10.1016/j.matdes.2008.04.042.

[11] Moreira, P. M. G. P. (2008). Lightweight stiffened panels: Mechanical characterization of emerging fabrication technologies. Submitted for the degree of Doctor Philosophy in Mechanical Engineering, Departamento de Engenharia Mecânica e Gestão Industrial, Faculdade de Engenharia da Universidade do Porto, Portugal.

[12] Chaves, F. J. P. et al. (2014). Fracture characterization of bonded joints using the dual actuator load apparatus. Journal of Adhesion Science and Technology, 28(5), pp. 512-524. DOI: 10.1080/01694243.2013.845357. 
[13] Gonçalves, D. J. S. et al. (2014). The use of the boundary element method in the analysis of single lap joints. Journal of Adhesion, 90(1), pp. 50-64. DOI: 10.1080/00218464.2013.763725.

[14] Campilho, R., Banea, M. D., and Silva, L. F. (2013). Tensile behavior of a structural adhesive at high temperatures by the extended finite element method. The Journal of Adhesion, 89, pp. 529-547. DOI: 10.1080/00218464.2013.768106.

[15] Banea, M. D. L., Silva, L. F., Campilho, R. D. and Sato, C. (2014). Smart adhesive joints: an overview of recent developments. The Journal of Adhesion, 90, pp. 16-40. DOI: 10.1080/00218464.2013.785916.

[16] Kadioglu, F. and Adams, R. D. (2015). Flexible adhesives for automotive application under impact loading. International Journal of Adhesion and Adhesives. Elsevier, 56, pp. 73-78. DOI: 10.1016/j.ijadhadh.2014.08.001.

[17] Schiel, M. et al. (2015). Behavior of adhesively bonded coated steel for automotive applications under impact loads. International Journal of Adhesion and Adhesives. Elsevier, 56, pp. 32-40. DOI: 10.1016/j.ijadhadh.2014.07.009.

[18] Jeenjitkaew, C., Luklinska, Z. and Guild, F. (2010). Morphology and surface chemistry of kissing bonds in adhesive joints produced by surface contamination. International Journal of Adhesion and Adhesives. Elsevier, 30(7), pp. 643653. DOI: $10.1016 /$ j.ijadhadh.2010.06.005.

[19] Sadowski, T., Golewski, P. and Zarzeka-Raczkowska, E. (2011). Damage and failure processes of hybrid joints: Adhesive bonded aluminium plates reinforced by rivets. Computational Materials Science. Elsevier B.V., 50(4), pp. 1256-1262. DOI: 10.1016/j.commatsci.2010.06.022.

[20] Sawa, T. and Kobayashi, T. (2006). The strength of joints combining an adhesive with a bolt. The Journal of Adhesion, 25(4):269-280. DOI: 10.1080/00218468808071267.

[21] Kwakernaak, A., Hofstede, J., Poulis, J. and Benedictus, R. (2012). Welding and joining of aerospace materials Improvements in bonding metals for aerospace and other applications, Delft University of Technology, The Netherlands. Woodhead Publishing Limited, pp. 235-280.

[22] Moroni, F., Pirondi, A. and Kleiner, F. (2010). Experimental analysis and comparison of the strength of simple and hybrid structural joints. International Journal of Adhesion and Adhesives, 30, pp. 367-379.

DOI: $10.1016 /$ j.ijadhadh.2010.01.005.

[23] Darwish, S. M. H. and Ghanya, A. (2000). Critical assessment of weld-bonded technologies. Journal of Materials Processing Technology, 105(3) pp. 221-229. DOI: 10.1016/S0924-0136(00)00592-6 105.

[24] Matweb (2018). Material Property Data. http://www.matweb.com.

[25] 3M TM AC-130. (2012). Technical datasheet. http://www.kirkside.com.au/Uploads/Images /araldite-420-ab.pdf.

[26] Adhesive. (2004). Data sheet. http://www.kirkside.com.au/Uploads/Images/araldite-420-a-b.pdf.

[27] Zhang, H., Wang, M., Zhang, X., Zhu, Z., Yu, T. and Yang, G. (2016). Effect of Welding Speed on Defect Features and Mechanical Performance of Friction Stir Lap Welded 7B04 Aluminum Alloy. Metals, 6(4), pp.87.

[28] Fratini, Buffa, G., Filice, L. and Gagliardi, F. (2005). Friction stir welding of AA6082-T6 T-joints: Process engineers and performance measurement. Proceedings of the Institution of Mechanical Engineers, part B: Journal of Engineering Manufacture, 220(5) pp.669. DOI: 101243/09544054JEM327.

[29] Richter-trummer, V. et al. (2012). Influence of the FSW clamping force on the final distortion and residual stress field. Materials Science \& Engineering A. Elsevier B.V., 538, pp. 81-88. DOI: 10.1016/j.msea.2012.01.016. 